\title{
Gender Differences and Comorbidities in U.S. Adults with Bipolar Disorder
}

\author{
Rikinkumar S. Patel ${ }^{1, *(\mathbb{D})}$, Sanya Virani ${ }^{2}$, Hina Saeed ${ }^{3}$, Sai Nimmagadda ${ }^{4}$, Jupi Talukdar ${ }^{5}$ and \\ Nagy A. Youssef 6 (iD) \\ 1 Department of Psychiatry, Griffin Memorial Hospital, 900 E Main St, Norman, OK 73071, USA \\ 2 Department of Psychiatry, Maimonides Medical Center, 4802 10th Ave, Brooklyn, NY 11219, USA; \\ svirani@maimonidesmed.org \\ 3 Baqai Medical University, 51, Deh Tor, Gadap Road, Super Highway, Karachi 74600, Pakistan; \\ hinasadeel@gmail.com \\ 4 University of Illinois College of Medicine, 1 Illini Dr, Peoria, IL 61605, USA; nimmagaddasaik@gmail.com \\ 5 Gauhati Medical College and Hospital, GMCH Rd, Bhangagarh, Guwahati, Assam 781032, India; \\ jupi1589@gmail.com \\ 6 Medical College of Georgia, Augusta University, 997 St. Sebastian Way, Augusta, GA 30912, USA; \\ NYOUSSEF@augusta.edu \\ * Correspondence: dr.rknpatel@gmail.com; Tel.: +1-(405)-573-2199
}

Received: 7 August 2018; Accepted: 30 August 2018; Published: 1 September 2018

\begin{abstract}
Background: Past studies have evaluated the association of various comorbidities with bipolar disorder. This study analyzes differences in the prevalence and association of medical and psychiatric comorbidities in bipolar patients by gender. Methods: A retrospective analysis was conducted using the Nationwide Inpatient Sample (2010-2014). Using International Classification of Diseases, 9th Revision, Clinical Modification (ICD-9-CM) codes, we narrowed the study population to comprise those with a primary diagnosis of bipolar disorder and then obtained information about comorbidities. The differences in comorbidities by gender were quantified using chi-square tests and the logistic regression model (odds ratio (OR)). Results: Hypertension (20.5\%), asthma $(12.5 \%)$ and hypothyroidism $(8.1 \%)$ were the top medical comorbidities found in bipolar patients. Migraine and hypothyroidism were seen three times higher in females $(\mathrm{OR}=3.074$ and $\mathrm{OR}=3.001$; respectively). Females with bipolar disorder had higher odds of comorbid inflammatory disorders like asthma $(\mathrm{OR}=1.755)$, Crohn's disease $(\mathrm{OR}=1.197)$ and multiple sclerosis $(\mathrm{OR}=2.440)$ compared to males. Females had a two-fold higher likelihood of comorbid post-traumatic stress disorder (PTSD) $(\mathrm{OR}=2.253)$ followed by personality disorders $(\mathrm{OR}=1.692)$ and anxiety disorders $(\mathrm{OR}=1.663)$ compared to males. Conclusion: Women with bipolar disorder have a much higher medical comorbidity burden than men and may highly benefit from an integrated team of physicians to manage their condition and improve their health-related quality of life.
\end{abstract}

Keywords: bipolar disorder; comorbidities; gender differences; inpatient psychiatry

\section{Introduction}

Bipolar disorder is a prevalent and chronic psychiatric illness that can be disabling if not well treated. It is commonly associated with comorbid systemic illnesses, morbidity, functional impairment and a high risk of suicide and mortality [1]. With proper diagnosis and treatment, patients can live productive and largely healthy lives. Although bipolar and unipolar disorders differ in some aspects, including treatment, they share common symptomatic and functional impairments, especially in depressive episodes. These disorders have some shared impairments in the white and grey matter 
compartments on brain imaging studies, but more white matter abnormalities have been reported in bipolar disease than in unipolar disorders. Brain imaging has been used to find the structural integrity of cortical white matter and grey matter [2]. Distinctive abnormalities of white matter connectivity and emotional and sensory neural circuitry are noted in bipolar disorders. These white matter abnormalities may be related to both axonal disorganization and demyelination or apoptosis [2].

Medical and psychiatric comorbidities of bipolar disorder have been a topic of increasing concern for healthcare providers, as patients with bipolar disorder may be at an increased risk of certain medical and other psychiatric conditions, which is the focus of this paper [3].

Though the rationale for the frequent existence of medical comorbidities in patients with bipolar disorder compared to other psychiatric illnesses is not fully understood, associations have been explored and explained by common risk factors, bidirectional causal factors and/or a common biological basis shared with certain medical conditions [4]. Increased comorbidities can be attributed to the genetic basis of the disorder. There seems to be some common genetic risk with conditions such as Alzheimer's disease, diabetes and coronary heart disease [5]. A general model of the genetics has been proposed that emphasizes the shared nature of common alleles in related common conditions, such as schizophrenia and bipolar disorder, diabetes and autoimmune diseases [5]. It has been shown that there is a substantial medical burden associated with bipolar disorder [6]. These patients can greatly benefit from an integrated team of healthcare providers [6].

The objective of this study is to analyze and discern the differences and burden of medical and psychiatric comorbidities in bipolar patients by gender. This is the first study using the Nationwide Inpatient Sample (NIS) data that explores the prevalence of various comorbidities in bipolar disorder in adult inpatients.

\section{Methods}

\subsection{Data Source}

A retrospective, cross-national, population-based analysis was performed using the Healthcare Cost and Utilization Project's (HCUP) NIS data from the years 2010 to 2014 [7]. The Agency for Healthcare Research and Quality (AHRQ) sponsors the HCUP databases, which are specifically designed to determine hospital outcomes and comorbidities related to the disease of interest. The HCUP-NIS database is the largest inpatient database comprising the administrative records from 4411 hospitals and covering 45 states in the United States [7]. The large sample size available via the database facilitated further recognition and analyses of rare comorbidities and special patient populations.

\subsection{Selection of Patients}

Based on the International Classification of Disease, Ninth Revision Clinical Modification (ICD-9-CM) diagnosis codes, we identified patients 18-50 years old with a primary diagnosis of bipolar disorder at the time of inpatient admission. In HCUP databases, more than 14,000 ICD-9-CM diagnosis codes have been mentioned. Bipolar disorder was identified using diagnosis codes 296.40, 296.41, 296.42, 296.43, 296.44, 296.50, 296.51, 296.52, 296.53, 296.54, 296.60, 296.61, 296.62, 296.63, 296.64 and 296.7.

\subsection{Variables of Interest}

The demographic variables examined in this study included age group (18-50 years), gender (male or female) and race (Caucasian, African American, Hispanic and other). Comorbidities were considered coexisting conditions to bipolar disorder, which is the primary disorder under this study [7]. Using ICD-9-CM codes, this variable identified various medical and psychiatric comorbidities in the patient records, as mentioned in Table 1. 
Table 1. International Classification of Disease, Ninth Clinical Modification (ICD-9-CM) codes used to identify comorbidities in patients with bipolar disorder.

\begin{tabular}{|c|c|}
\hline Comorbidity & ICD-9-CM Diagnosis Code \\
\hline \multicolumn{2}{|l|}{ Medical Comorbidities } \\
\hline Hypertension & $\begin{array}{c}401.1,401.9,642.00-642.04,401.0,402.00-405.99,437.2,642.10-642.24 \\
642.70-642.94\end{array}$ \\
\hline Diabetes & 249.00-249.31, 250.00-250.33, 648.00-648.04 \\
\hline Obesity & $\begin{array}{c}278.0,278.00,278.01,278.03,649.10-649.14,793.91, \text { V85.30-V85.39, } \\
\text { V85.41-V85.45, V85.54 }\end{array}$ \\
\hline Hypothyroidism & $243-244.2,244.8,244.9$ \\
\hline Migraine & $\begin{array}{c}339.00-339.05,339.09-339.12,339.20-339.22,339.3,339.41-339.44 \\
339.81-339.85,339.89,346.0,346.00-346.03,346.1,346.10-346.13,346.2 \\
346.20-346.23,346.30-346.33,346.40-346.43,346.50-346.53 \\
346.70-346.73,346.8,346.80-346.83,346.9,346.90-346.93,784.0\end{array}$ \\
\hline Crohn's Disease & $560.89,560.9$ \\
\hline Multiple Sclerosis & 340 \\
\hline Asthma & 493.00-493.02, 493.10-493.12, 493.20-493.22, 493.81, 493.82, 493.90-493.92 \\
\hline \multicolumn{2}{|l|}{ Psychiatric Comorbidities } \\
\hline Drug abuse & $292.0,292.82-292.89,292.9,304.00-304.93,305.20-305.93,648.30-648.34$ \\
\hline Alcohol abuse & $\begin{array}{c}\text { 291.0-291.3, 291.5, 291.8, 291.81, 291.82, 291.89, 291.9, 303.00-303.93, } \\
\text { 305.00-305.03 }\end{array}$ \\
\hline Anxiety disorder & $\begin{array}{c}293.84,300.00-300.02,300.09,300.10,300.20-300.23,300.29,300.3,300.5, \\
300.89,300.9,308.0-308.4,308.9,309.81,313.0,313.1,313.21,313.22,313.3, \\
313.82,313.83\end{array}$ \\
\hline Personality disorder & $\begin{array}{c}301.0,301.10-301.13,301.20-301.22,301.3,301.4,301.50,301.51,301.59 \\
301.6,301.7,301.81-301.84,301.89,301.9\end{array}$ \\
\hline PTSD & 309.81 \\
\hline ADHD & $314.00,314.01$ \\
\hline Eating disorder & $307.1,307.50-307.54,307.59$ \\
\hline
\end{tabular}

\subsection{Approaches}

This study was performed using the HCUP-NIS database, focusing on the determination of the comorbidities for patients with bipolar disorder. Descriptive statistics and cross tabulation were used to summarize the results. Pearson's Chi-square test and independent sample $t$-test were used for categorical data and continuous data, respectively. We used a logistic regression model to measure the associations between females and males (reference category) in terms of medical and psychiatric comorbidities. We applied discharge weights in all regression models to obtain nationally representative inpatient data, whereas age and race were adjusted. A $p$ value $<0.01$ was used as a reference to determine the statistical significance test result. All statistical analyses were done by SPSS version 23 (International Business Machines Corporation, Armonk, NY, USA) in this study [8].

\subsection{Ethical Approval}

Our study database did not contain patient identifiable information. To protect the privacy of individual patients, physicians and hospitals, the state and hospital identifiers were all de-identified; this database is available as a public database. The use of this administrative database under the HCUP, according to the Agency for Healthcare Research and Quality (AHRQ) of the U.S. Department of Health and Human Services, does not require approval from an Institutional Review Board (IRB), because the NIS is publicly available and is a fully de-identified database. 


\section{Results}

\subsection{Sample Characteristics}

We analyzed 593,257 patients admitted for bipolar disorder from 2010 to 2014; 53.3\% were young adults (18-35 years of age) and 54.8\% were females. About two-thirds of the sample population was Caucasian (69.8\%) followed by African American (16.8\%) and Hispanic (8.4\%).

\subsection{Medical and Psychiatric Comorbidities}

Hypertension (20.5\%), asthma (12.5\%) and hypothyroidism (8.1\%) were the top three medical comorbidities found in bipolar patients. Migraine and hypothyroidism were seen three times higher in females $(\mathrm{OR}=3.074$ and $\mathrm{OR}=3.001$; respectively). Females with bipolar disorder had higher odds of comorbid inflammatory disorders like asthma $(\mathrm{OR}=1.755)$, Crohn's disease $(\mathrm{OR}=1.197)$ and multiple sclerosis $(\mathrm{OR}=2.440)$ compared to men. Among the cardiometabolic comorbidities, females had higher odds of obesity $(\mathrm{OR}=2.011)$ followed by diabetes $(\mathrm{OR}=1.159)$. The gender-wise distribution of comorbidities in patients with bipolar disorder is shown in Figure 1.

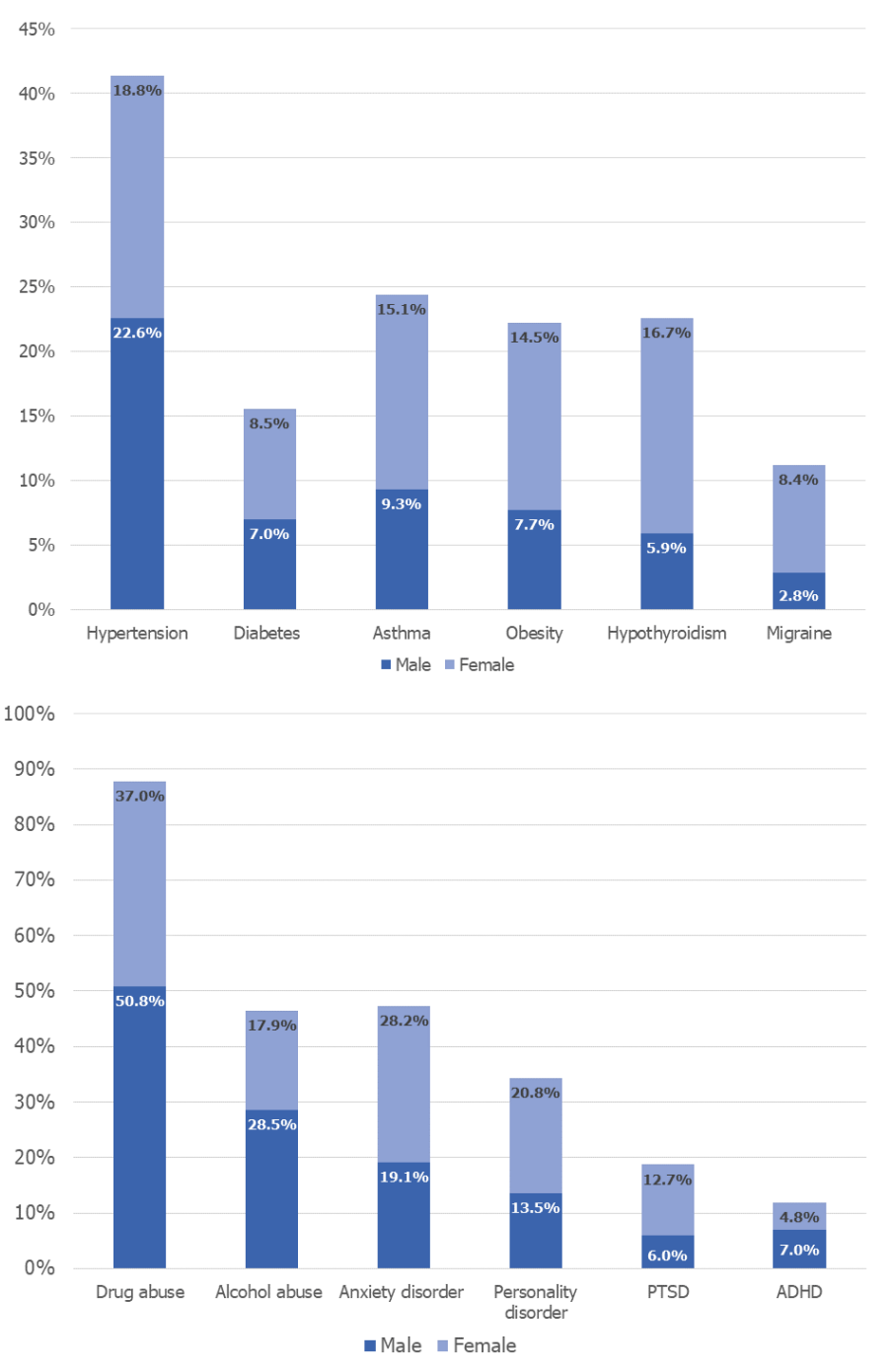

Figure 1. Gender-wise distribution of comorbidities in patients with bipolar disorder. The proportion of males and females with bipolar disorder were obtained using cross tabulation and the Pearson Chi-Square $\left(\chi^{2}\right)$ test, and were significant with $p$ value $\leq 0.01$ at a 95\% confidence interval. PTSD: Post-traumatic stress disorder; ADHD: Attention-deficit/hyperactivity disorder. 
Among substance use disorders, $50.8 \%$ of males with bipolar disorder had a co-diagnosis of drug abuse and $28.5 \%$ had alcohol abuse. On the contrary, females had lower odds of these substance-use disorders than males. The most common psychiatric illness associated with bipolar disorder was anxiety disorder (24.1\%) followed by personality disorder (17.5\%) and PTSD (9.7\%). Females had twice the odds of comorbid PTSD $(\mathrm{OR}=2.253)$ followed by personality disorder and anxiety disorder $(\mathrm{OR}=1.692$ and $\mathrm{OR}=1.663$; respectively). Although eating disorders were seen in very low proportions of bipolar patients $(0.1 \%$ males and $0.6 \%$ females), females had about 11 times higher odds of this comorbidity compared to men $(\mathrm{OR}=11.673)$. The association of comorbidities in females is shown in Table 2.

Table 2. Odds of medical and psychiatric comorbidities with bipolar disorder in females compared with males.

\begin{tabular}{|c|c|c|c|}
\hline \multirow{2}{*}{ Comorbidities } & \multicolumn{3}{|c|}{ Logistic Regression Model } \\
\hline & OR & $95 \% \mathrm{CI}$ & $p$ \\
\hline \multicolumn{4}{|l|}{ Medical Comorbidities } \\
\hline Hypertension & 0.721 & $0.711-0.731$ & $<0.0001$ \\
\hline Diabetes & 1.159 & $1.136-1.182$ & $<0.0001$ \\
\hline Obesity & 2.011 & $1.976-2.046$ & $<0.0001$ \\
\hline Hypothyroidism & 3.001 & $2.936-3.069$ & $<0.0001$ \\
\hline Migraine & 3.074 & 2.995-3.155 & $<0.0001$ \\
\hline Asthma & 1.755 & $1.726-1.783$ & $<0.0001$ \\
\hline Crohn's disease & 1.197 & $1.108-1.293$ & $<0.0001$ \\
\hline Multiple Sclerosis & 2.440 & $2.183-2.727$ & $<0.0001$ \\
\hline \multicolumn{4}{|c|}{ Psychiatric Comorbidities } \\
\hline Drug abuse & 0.573 & $0.567-0.579$ & $<0.0001$ \\
\hline Alcohol abuse & 0.529 & $0.523-0.536$ & $<0.0001$ \\
\hline Anxiety disorder & 1.663 & $1.643-1.684$ & $<0.0001$ \\
\hline Personality disorder & 1.692 & $1.668-1.716$ & $<0.0001$ \\
\hline PTSD & 2.253 & $2.211-2.296$ & $<0.0001$ \\
\hline ADHD & 0.699 & $0.683-0.714$ & $<0.0001$ \\
\hline Eating disorder & 11.673 & $9.914-13.744$ & $<0.0001$ \\
\hline
\end{tabular}

Significant $p$ values $\leq 0.01$ at 95\% Confidence Interval. Odds Ratio generated by binomial logistic regression model and was adjusted for age and race. OR: Odds ratio; CI: Confidence interval; PTSD: Post-traumatic stress disorder; ADHD: Attention-deficit/hyperactivity disorder.

\section{Discussion}

This study of population-based hospital data from patients with bipolar disorder reveals the association with various medical and psychiatric comorbidities and gender differences. Hypertension was the most common comorbidity in bipolar patients (20.5\%), but was lower when compared to the general global population, as mentioned in a systematic study from $2000-2010$ (28.5\% in high-income countries and $31.5 \%$ in low- and middle-income countries) [9] and the recent report stating that hypertension is seen in $30.2 \%$ of men and $27.7 \%$ of women in the general population [10]. Many psychotropic medications such as tricyclic antidepressants can induce hypotension, which can mask the symptoms of hypertension during routine health check-ups. Thus, the number of hypertensive patients with bipolar disorder could potentially be lower [11]. Another possible reason for the lower number of bipolar patients with hypertension could be due to fewer follow-up visits of mental and behavioral patients to the primary health clinics [12]. As per the Global Asthma Report, about $8.6 \%$ of 
young adults (age 18-45) experienced the symptoms of asthma in 2014, whereas comorbid asthma was seen in a higher proportion of bipolar patients (12.5\%) in our study [13]. Hypothyroidism was seen in $8.1 \%$ bipolar patients in our study population, which was two times higher than that seen in the general US population (4.6\%) as per the recent report by the Endocrine Society [14]. Bipolar disorder has been found to have strong affiliations with thyroid dysfunction, whether the interaction of lithium is considered or not $[15,16]$. Previous studies have provided evidence linking hypothyroidism with bipolar disorder, with a notable association with manic relapse [17] and rapid cycling bipolar disorder [18]. Our data results also showed an increased association of thyroid dysfunction with bipolar disorder. Hypothyroidism was the third most common medical comorbidity in bipolar patients. Also, females with bipolar disorder in this study had a three-fold higher likelihood of comorbid hypothyroidism compared to males. Migraines also had a remarkable association in females with bipolar disease in our study; they were three times more likely to have migraines as a comorbidity than males. There exists a higher percentage of the co-occurrence of migraines and bipolar disorders, predominantly in subjects with a confirmed family history of bipolar disorder, suicidal attempts and childhood physical abuse [19]. In addition to the higher prevalence ranging from 30 to $34.8 \%$ [20,21], patients with bipolar disorders and migraines were also found to have a complex course of the disease with more severe and an increased number of depressive episodes, as well as suicidality [22]. Oxidative stress and inflammation in cross sensitization between bipolar disorder and migraine has been hypothesized as a possible explanation [22]. Genetic factors are also thought to be implicated in the co-occurrence of migraine and bipolar disorders. In addition, inflammatory mechanisms involving abnormal cytokine activation and abnormal arachidonic acid metabolism have also been postulated as a common pathogenesis [23]. Both of these disorders also demonstrated higher neuroticism, which might, in part, explain the co-occurrence [23]. Similar to that seen in our study, the prevalence of migraine is also higher in females in the general population than males (19.1\% vs. $9 \%)$ [24], though this comorbidity has a lower overall prevalence compared to that present in bipolar patients $(8.4 \%$ in females and $2.8 \%$ in males).

Bipolar disorder has been associated with many autoimmune disorders and few studies have indicated the coexistence of multiple sclerosis [25-27]. The involvement of the human leukocyte antigen (HLA) gene complex has been postulated as one of the possible explanations for this increased susceptibility [24]. Analysis of our data also suggests a possible linkage of bipolar and multiple sclerosis. Females with bipolar disorder were found to have about three times the likelihood of having multiple sclerosis (as a comorbidity) compared to males. Some studies have shown that bipolar disorder is highly prevalent in patients with asthma and, therefore, suggest a further increased risk with the use of a higher prednisone dose [28,29]. Potential shared genetic vulnerability has also been proposed [30] as a possible explanation for this association. However, no precise etiology for this co-occurrence has been established. The female participants in our study were about two times more likely to have comorbid asthma compared to the male participants. Depression and anxiety disorders have been more frequently reported to be associated with inflammatory bowel disease [31], but previous studies were not able to establish a strong association of bipolar disorder with Crohn's disease. Nevertheless, we found a marginally higher likelihood of a co-diagnosis of Crohn's disease in females than males.

Metabolic derangements resulting in obesity and diabetes are commonly reported with bipolar disorder [32,33]. Many mechanisms have been suggested for these findings. Impaired glucose metabolism, poor quality of life and commonly associated eating disorders are implicated in these dysregulations [34,35]. Women with bipolar disorder, when compared to men with bipolar disorder, have higher rates of abdominal obesity as per a systematic review conducted by Baskaran et al. [36]. As per the National Diabetes Statistics Report (2017), diabetes is seen in 14.9\% of women and $15.3 \%$ of men, which is much higher than that seen in the bipolar patients in this study [37]. Nonetheless, bipolar females had a higher risk of obesity and diabetes than the male participants in our study. The National Health Interview Survey 1997-2012 concluded that comorbid obesity is present in $38.3 \%$ of 
women and $34.3 \%$ of men [38], which is about three times higher than that seen in the bipolar patients in our study. Unlike the above reports, diabetes and obesity seem to be lower in the bipolar inpatient population, yet the odds of these comorbidities were higher in females with bipolar disorder compared to males.

Among all of the listed psychiatric comorbidities, female patients with bipolar disorder were found to be most vulnerable to having post-traumatic stress disorder (PTSD). These results are consistent with the findings of previous studies that indicated the co-occurrence of PTSD with bipolar disorder at significantly higher odds $[39,40]$. These studies revealed a significant co-occurrence of PTSD with bipolar disorder in both veterans and the civilian population. The bipolar patients had a higher prevalence of comorbid PTSD in our study compared to that seen in the general population. A recent National Institute of Mental Health (NIMH) survey states that PTSD is present in $18 \%$ of males and $5.2 \%$ of females [41], and personality disorder is present in $9.1 \%$ of the general population [42]. The females with bipolar disorder in our study showed a 1.7 times higher association with personality disorders and anxiety disorder than males with bipolar disorder. Among the personality disorders, some similarities have been found between bipolar disorder and borderline personality disorder, although there are still many differences. Dysfunction of the dopaminergic and serotonergic systems, changes in limbic system, as well as the size of the amygdala have been proposed in the pathophysiology of both disorders [43].

Past studies have found a strong association of anxiety disorder with bipolar disorder [44,45]. We found that females with bipolar disorder were 1.6 times more likely to suffer from anxiety disorder compared to males. When compared with the general population, bipolar patients had a higher prevalence of comorbid anxiety in males ( $14.3 \%$ vs. $19.1 \%$ seen in bipolar patients) and females $(23.4 \%$ vs. $28.2 \%$ seen in bipolar patients) [46]. An eating disorder was present in a very low proportion of total patients $(0.1 \%$ males and $0.6 \%$ females), which is lower than that seen in the general population ( $0.4 \%$ males and $1 \%$ females) [47]. However, the females with bipolar disorder had 11 -fold higher odds of having eating disorders with bipolar disorder than males in our study. There is an increased coexistence of bipolar disease with eating disorders in female patients, predominantly bulimia and anorexia nervosa [48,49]. In addition, the coexistence of bipolar disorder with an eating disorder has been reported to be associated with poor long-term outcomes and a severe disease course of bipolar disorder [49,50]. Alcohol use disorder and substance use disorder were seen in $8.4 \%$ and $12.5 \%$ of men, and $4.2 \%$ and $7.9 \%$ of women, respectively, in the general population [51,52], which is much lower than what is seen in the inpatient bipolar population in our study.

Furthermore, our study did have some limitations. Firstly, this study was based on an administrative database and lacks patient-level clinical information. NIS data regarding bipolar disorder are limited to inpatient hospitalization only and do not include any data from outpatient settings. Re-hospitalizations, which add to the total inpatient burden, are not accounted for in our study, given the nature of the data. Selection bias is possible, given the retrospective nature of the study. The prevalence of comorbidities in the study participants may differ than that seen in the general population and other bipolar populations, as our participants were selected from the hospital admissions and the inpatient database. However, despite these limitations, NIS is still an excellent inpatient population-based representation of disease associations and comorbidities. Despite the retrospective nature of the study, the chances of recall bias are probably minimal, given that it is an administrative database with primary and secondary diagnosis codes and other clinical information collected at the time of inpatient management, as well as on discharge. The main strength of this study is the nationally representative sample provided by the NIS dataset [7], as well as a uniform collection of data obtained over five years through ICD-9-CM diagnosis codes. Another important strength is its large sample size of 593,257 and the reliability of the data, given that the information is coded independently of the individual practitioner; therefore, this would minimize reporting bias, as the large sample size increases power in detecting differences. 


\section{Conclusions}

Through this retrospective nationwide study, we found that women with bipolar disorder have a greater risk and comorbidity with autoimmune and inflammatory disorders than men. Medical and psychiatric comorbidities can substantially add to impairment in function if not treated. These psychiatric comorbidities include anxiety disorders, PTSD, eating disorders and personality disorders. PTSD was the most common psychiatric co-morbidity in bipolar patients. These added comorbidities can substantially increase the disease burden of patients with bipolar disorder. Women with bipolar disorder are at an even more increased risk than men and integrating care among primary care physicians and psychiatrists closely can greatly improve the health-related quality of life and vastly decrease the burden of illness and complications. This can be attained by closer and more frequent checks and follow-ups for medical comorbidities for female patients with bipolar disorder, along with aggressive control of the physical comorbidities. During the follow-up visits, the patients should be educated by providing clear, written instructions regarding health education and directions. Frequent bipolar psychiatric comorbidities like PTSD and substance use or alcohol use disorders are either undetected or under-treated. We recommend thorough psychiatric interviewing and necessary laboratory tests for early diagnosis and treatment of these comorbidities. This could improve the overall psychiatric care for patients with bipolar disorder. Appropriate and regular communication between the primary care physicians and psychiatrists managing the bipolar patients is required in order to maximize integration and provide high-quality health care. We recommend an integrated care model, involving psychiatrists and primary care physicians to improve treatment of both the psychiatric and medical comorbidities in these patients.

Author Contributions: R.S.P.: Conceptualization, methodology and software, validation, formal analysis, investigation resources and data curation, writing-original draft preparation, writing-review \& editing, visualization, supervision and project administration. S.V.: Writing-review \& editing, validation and supervision. H.S.: Writing—original draft preparation, writing—review \& editing. S.N.: Writing一original draft preparation, writing-review \& editing. J.T.: Writing-original draft preparation, writing-review \& editing. N.A.Y.: Conceptualization of the concept, writing, reviewing \& editing, supervision of the and mentoring on the concepts literature and manuscript writing and finalization.

Funding: This research did not receive any specific grant from funding agencies in the public, commercial, or not-for-profit sectors.

Conflicts of Interest: The authors report no conflict of interest.

\section{References}

1. Leboyer, M.; Soreca, I.; Scott, J.; Frye, M.; Henry, C.; Tamouza, R.; Kupfer, D.J. Can bipolar disorder be viewed as a multi-system inflammatory disease? J. Affect. Disord. 2012, 141, 1-10. [CrossRef] [PubMed]

2. Serafini, G.; Borgwardt, S.; Houenou, J.; Geoffroy, P.; Jardri, R.; Girardi, P.; Amore, M. Brain changes in early-onset bipolar and unipolar depressive disorders: A systematic review in children and adolescents. Eur. Child Adolesc. Psychiatry 2014, 23, 1023-1041. [CrossRef] [PubMed]

3. Forty, L.; Ulanova, A.; Jones, L.; Jones, I.; Gordon-Smith, K.; Fraser, C.; Farmer, A.; McGuffin, P.; Lewis, C.M.; Hosang, G.M. Comorbid medical illness in bipolar disorder. Br. J. Psychiatry 2014, 205, 465-472. [CrossRef] [PubMed]

4. Schoepf, D.; Heun, R. Bipolar disorder and comorbidity: Increased prevalence and increased relevance of comorbidity for hospital-based mortality during a 12.5-year observation period in general hospital admissions. J. Affect. Disord. 2014, 169, 170-178. [CrossRef] [PubMed]

5. Kerner, B. Genetics of bipolar disorder. Appl. Clin. Genet. 2014, 7, 33-42. [CrossRef] [PubMed]

6. Sylvia, L.G.; Shelton, R.; Kemp, D.E.; Bernstein, E.E.; Friedman, E.S.; Brody, B.D.; McElroy, S.L.; Singh, V.; Tohen, M.; Bowden, CL. Medical burden in bipolar disorder: Findings from the Clinical and Health Outcomes Initiative in Comparative Effectiveness for Bipolar Disorder study (Bipolar CHOICE). Bipolar Disord. 2015, 17, 212-223. [CrossRef] [PubMed]

7. NIS Description of Data Elements. Healthcare Cost and Utilization Project (HCUP). Available online: https: / / www.hcup-us.ahrq.gov/db/nation/nis/nisdde.jsp (accessed on 9 July 2018). 
8. IBM SPSS Statistics for Windows, Version 23.0. Available online: https://www.ibm.com/products/spssstatistics (accessed on 9 July 2018).

9. Mills, K.T.; Bundy, J.D.; Kelly, T.N.; Reed, J.E.; Kearney, P.M.; Reynolds, K.; Chen, J.; He, J. Global Disparities of Hypertension Prevalence and Control: A Systematic Analysis of Population-Based Studies from 90 Countries. Circulation 2016, 134, 441-450. [CrossRef]

10. Hypertension Prevalence and Control among Adults: United States, 2015-2016. Available online: https: / / www.cdc.gov/nchs/products/databriefs/db289.htm (accessed on 9 July 2018).

11. Lindsey, P.L. Psychotropic medication use among older adults: What all nurses need to know. J. Gerontol. Nurs. 2009, 35, 28-38. [CrossRef] [PubMed]

12. Gerber, M.R.; Cabral, H.J.; Suglia, SF.; Joseph, R.C.; Fried, L.E. Patient follow-up in primary care after behavioral health screening in an urban public hospital system: A prospective, observational study of 2686 paients. Prim Care Companion J. Clin. Psychiatry 2008, 10, 430-434. [CrossRef] [PubMed]

13. The Global Asthma Report 2014. Available online: http://globalasthmareport.org/burden/burden.php (accessed on 9 July 2018).

14. Endocrine Facts and Figures. Available online: http:/ / endocrinefacts.org/ (accessed on 9 July 2018).

15. Ozerdem, A.; Tunca, Z.; Çımrın, D.; Hıdıroğlu, C.; Ergör, Gl. Female vulnerability for thyroid function abnormality in bipolar disorder: Role of lithium treatment. Bipolar Disord. 2014, 16, 72-82. [CrossRef] [PubMed]

16. Cremaschi, L.; Kardell, M.; Johansson, V.; Isgren, A.; Sellgren, C.M.; Altamura, A.C.; Hultman, C.M.; Landén, M. Prevalences of autoimmune diseases in schizophrenia, bipolar I and II disorder, and controls. Psychiatry Res. 2017, 258, 9-14. [CrossRef] [PubMed]

17. Amann, B.L.; Radua, J.; Wunsch, C.; König, B.; Simhandl, C. Psychiatric and physical comorbidities and their impact on the course of bipolar disorder: A prospective, naturalistic 4-year follow-up study. Bipolar Disord. 2017, 19, 225-234. [CrossRef] [PubMed]

18. Chakrabarti, S. Thyroid functions and bipolar affective disorder. J. Thyroid Res. 2011, 306-367. [CrossRef] [PubMed]

19. Kivilcim, Y.; Altintas, M.; Domac, F.M.; Erzincan, E.; Gülec, H. Screening for bipolar disorder among migraineurs: The impact of migraine-bipolar disorder comorbidity on disease characteristics. Neuropsychiatr. Dis. Treat. 2017, 13, 631-641. [CrossRef] [PubMed]

20. Fornaro, M.; Stubbs, B. A meta-analysis investigating the prevalence and moderators of migraines among people with bipolar disorder. J. Affect. Disord. 2015, 178, 88-97. [CrossRef] [PubMed]

21. Leo, R.J.; Singh, J. Migraine headache and bipolar disorder comorbidity: A systematic review of the literature and clinical implications. Scand. J. Pain 2016, 11, 136-145. [CrossRef] [PubMed]

22. Da Costa, S.C.; Passos, I.C.; Réus, G.Z.; Carvalho, A.F.; Soares, J.C.; Quevedo, J. The Comorbidity of Bipolar Disorder and Migraine: The Role of Inflammation and Oxidative and Nitrosative Stress. Curr. Mol. Med. 2016, 16, 179-186. [CrossRef] [PubMed]

23. Saunders, E.F.; Nazir, R.; Kamali, M.; Ryan, K.A.; Evans, S.; Langenecker, S.; Gelenberg, A.J.; McInnis, M.G. Gender differences, clinical correlates, and longitudinal outcome of bipolar disorder with comorbid migraine. J. Clin. Psychiatry 2014, 75, 512-519. [CrossRef] [PubMed]

24. Burch, R.C.; Loder, S.; Loder, E.; Smitherman, T.A. The prevalence and burden of migraine and severe headache in the United States: Updated statistics from government health surveillance studies. Headache 2015, 55, 21-34. [CrossRef] [PubMed]

25. Bozikas, V.P.; Anagnostouli, M.C.; Petrikis, P.; Sitzoglou, C.; Phokas, C.; Tsakanikas, C.; Karavatos, A. Familial bipolar disorder and multiple sclerosis: A three-generation HLA family study. Prog. Neuropsychopharmacol. Biol. Psychiatry 2003, 27, 835-839. [CrossRef]

26. Schiffer, R.B.; Wineman, N.M.; Weitkamp, L.R. Association between bipolar affective disorder and multiple sclerosis. Am. J. Psychiatry 1986, 143, 94-95.

27. Cerqueira, A.C.; Nardi, A.E.; Souza-Lima, F.; Godoy-Barreiros, J.M. Bipolar disorder and multiple sclerosis: Comorbidity and risk factors. Rev. Bras. Psiquiatr. 2010, 32, 454-456. [CrossRef] [PubMed]

28. Wu, M.K.; Wang, H.Y.; Chen, Y.W.; Lin, P.Y.; Wu, C.K.; Tseng, P.T. Significantly Higher Prevalence Rate of Asthma and Bipolar Disorder Co-Morbidity: A Meta-Analysis and Review Under PRISMA Guidelines. Medicine (Baltim) 2016, 95, 3217. [CrossRef] [PubMed] 
29. Lin, T.C.; Lee, C.T.; Lai, T.J.; Lee, C.T.; Lee, K.Y.; Chen, V.C.; Stewart, R. Association of asthma and bipolar disorder: A nationwide population-based study in Taiwan. J. Affect. Disord. 2014, 168, 30-36. [CrossRef] [PubMed]

30. Wu, Q.; Dalman, C.; Karlsson, H.; Lewis, G.; Osborn, D.P.J.; Gardner, R.; Hayes, J.F. Childhood and Parental Asthma, Future Risk of Bipolar Disorder and Schizophrenia Spectrum Disorders: A Population-Based Cohort Study. Schizophr. Bull. 2018. [CrossRef] [PubMed]

31. Nowakowski, J.; Chrobak, A.A.; Dudek, D. Psychiatric illnesses in inflammatory bowel diseases-Psychiatric comorbidity and biological underpinnings. Psychiatr. Pol. 2016, 50, 1157-1166. [CrossRef] [PubMed]

32. Barandas, R.; Landgraf, D.; McCarthy, M.J.; Welsh, D.K. Circadian Clocks as Modulators of Metabolic Comorbidity in Psychiatric Disorders. Curr. Psychiatry Rep. 2015, 17, 98. [CrossRef] [PubMed]

33. Vancampfort, D.; Mitchell, A.J.; De Hert, M.; Sienaert, P.; Probst, M.; Buys, R.; Stubbs, B. Prevalence and predictors of type 2 diabetes mellitus in people with bipolar disorder: A systematic review and meta-analysis. J. Clin. Psychiatry 2015, 76, 1490-1499. [CrossRef] [PubMed]

34. Abrahamian, H.; Kautzky-Willer, A.; Rießland-Seifert, A.; Fasching, P.; Ebenbichler, C.; Hofmann, P.; Toplak, H. Mental disorders and diabetes mellitus. Wien. Klin. Wochenschr. 2016, 128, 170-178. [CrossRef] [PubMed]

35. Leopold, K.; Reif, A.; Haack, S.; Bauer, M.; Bury, D.; Löffler, A.; Kittel-Schneider, S.; Pfeiffer, S.; Sauer, C.; Schwarz, P. Type 2 diabetes and pre-diabetic abnormalities in patients with bipolar disorders. J. Affect. Disord. 2016, 189, 240-245. [CrossRef] [PubMed]

36. Baskaran, A.; Cha, D.S.; Powell, A.M.; Jalil, D.; McIntyre, R.S. Sex differences in rates of obesity in bipolar disorder: Postulated mechanisms. Bipolar Disord. 2014, 16, 83-92. [CrossRef] [PubMed]

37. National Diabetes Statistics Report in National Center for Chronic Disease Prevention and Health Promotion 2017. Available online: https://www.cdc.gov/diabetes/pdfs/data/statistics/national-diabetes-statisticsreport.pdf (accessed on 9 July 2018).

38. Arroyo-Johnson, C.; Mincey, K.D. Obesity Epidemiology Worldwide. Gastroenterol. Clin. N. Am. 2016, 45, 571-579. [CrossRef] [PubMed]

39. ÓConghaile, A.; Smedberg, D.L.; Shin, A.L.; DeLisi, L.E. Familial risk for psychiatric disorders in military veterans who have post-traumatic stress disorder with psychosis: A retrospective electronic record review. Psychiatr. Genet. 2018, 28, 24-30.

40. Okkels, N.; Trabjerg, B.; Arendt, M.; Pedersen, C.B. Traumatic Stress Disorders and Risk of Subsequent Schizophrenia Spectrum Disorder or Bipolar Disorder: A Nationwide Cohort Study. Schizophr. Bull. 2017, 43, 180-186. [CrossRef] [PubMed]

41. Post-Traumatic Stress Disorder (PTSD). Available online: https:/ /www.nimh.nih.gov/health/statistics / post-traumatic-stress-disorder-ptsd.shtml (accessed on 9 July 2018).

42. Personality Disorders. Available online: https://www.nimh.nih.gov/health/statistics/personalitydisorders.shtml (accessed on 9 July 2018).

43. Antoniadis, D.; Samakouri, M.; Livaditis, M. The association of bipolar spectrum disorders and borderline personality disorder. Psychiatr. Q. 2012, 83, 449-465. [CrossRef] [PubMed]

44. Rihmer, Z.; Szádóczky, E.; Füredi, J.; Kiss, K.; Papp, Z. Anxiety disorders comorbidity in bipolar I, bipolar II and unipolar major depression: Results from a population-based study in Hungary. J. Affect. Disord. 2001, 67, 175-179. [CrossRef]

45. Simon, N.M.; Otto, M.W.; Wisniewski, S.R.; Fossey, M.; Sagduyu, K.; Frank, E.; Sachs, G.S.; Nierenberg, A.A.; Thase, M.E.; Pollack, M.H. Anxiety disorder comorbidity in bipolar disorder patients: Data from the first 500 participants in the Systematic Treatment Enhancement Program for Bipolar Disorder (STEP-BD). Am. J. Psychiatry 2004, 161, 2222-2229. [CrossRef] [PubMed]

46. Any Anxiety Disorder. Available online: https://www.nimh.nih.gov/health/statistics/any-anxietydisorder.shtml (accessed on 27 August 2018).

47. Eating Disorders. Available online: https://www.nimh.nih.gov/health/statistics/eating-disorders.shtml (accessed on 27 August 2018).

48. Hudson, J.I.; Pope, H.G., Jr.; Jonas, J.M.; Yurgelun-Todd, D. Phenomenologic relationship of eating disorders to major affective disorder. Psychiatry Res. 1983, 9, 345-354. [CrossRef] 
49. McElroy, S.L.; Frye, M.A.; Hellemann, G.; Altshuler, L.; Leverich, G.S.; Suppes, T.; Keck, P.E.; Nolen, W.A.; Kupka, R. Prevalence and correlates of eating disorders in 875 patients with bipolar disorder. J. Affect. Disord. 2011, 128, 191-198. [CrossRef] [PubMed]

50. Kupfer, D.J. The increasing medical burden in bipolar disorder. JAMA 2005, 293, 2528-2530. [CrossRef] [PubMed]

51. Alcohol Facts and Statistics. Available online: https://www.niaaa.nih.gov/alcohol-health/overviewalcohol-consumption/alcohol-facts-and-statistics (accessed on 27 August 2018).

52. National Center for Health Statistics-Illegal Drug Use. Available online: https://www.cdc.gov/nchs/fastats/ drug-use-illegal.htm (accessed on 27 August 2018).

2018 by the authors. Licensee MDPI, Basel, Switzerland. This article is an open access article distributed under the terms and conditions of the Creative Commons Attribution (CC BY) license (http://creativecommons.org/licenses/by/4.0/). 